\title{
POLA OSMOREGULASI UDANG VANNAMEI (LITOPENAEUS VANNAMEI) DEWASA YANG DIABLASI DAN DIKULTIVASI PADA BERBAGAI TINGKAT SALINITAS
}

\author{
Mutiara Salsabiela \\ Akademi Minyak dan Gas Balongan, Indramayu, Jl. Soekarno Hatta, Pekandangan, Kec. Indramayu, \\ Kabupaten Indramayu, Jawa Barat 45216 mutiara.salsabiela62@gmail.com \\ Diterima 3 Maret 2020, disetujui 30 April 2020, diterbitkan 30 April 2020 \\ Pengutipan: Salsabiela, M. (2020). Pola Osmoregulasi Udang Vannamei (Litopenaeus Vannamei) Dewasa \\ Yang Diablasi dan Dikultivasi pada Berbagai Tingkat Salinitas. Gema Wiralodra, Vol 11, No \\ 1, Hal 143-153, April 2020
}

\begin{abstract}
ABSTRAK
Tujuan dari penelitian ini adalah untuk mengkaji pola osmoregulasi, L. vannamei dewasa yang diablasi dan dikultivasi pada media dengan salinitas berbeda. Metode yang digunakan adalah eksperimental laboratories dengan Rancangan Acak Sistematis (RAS) dengan 4 perlakuan dan 3 ulangan pada tiap perlakuannya. Perlakuan yang diujikan adalah salinitas dengan perlakuan S1 (10 ppt, 289,20 mOsm/ $/ \mathrm{H}_{2} \mathrm{O}$ isosmotik postmolt), $\mathrm{S} 2$ (15 ppt, 432,80 mOsm/ $/ \mathrm{H}_{2} \mathrm{O}$ isosmotik intermolt awal), S3 (25 \pm 1 ppt,725,15 mOsm/l $\mathrm{H}_{2} \mathrm{O}$ isosmotik intermolt akhir) dan S4 (29 \pm 1 ppt, 820,10 $\mathrm{mOsm} / 1 \mathrm{H}_{2} \mathrm{O}$ isosmotik molt). Penelitian ini dilaksanakan selama 60 hari. Data dianalisis dengan analisis varian (ANOVA) satu jalur, dan untuk mengetahui perbedaan pengaruh antar perlakuan dilakukan uji wilayah ganda Duncan. Hasil ANOVA menunjukkan bahwa salinitas berpengaruh terhadap Tingkat Kerja Osmotik (TKO), frekuensi molting dan laju pertumbuhan harian (sebelum dan setelah mengalami kematian), namun tidak berpengaruh terhadap kelulushidupan (SR). TKO terendah berada pada perlakuan S3 (25 \pm 1 ppt) sebesar $1,01 \mathrm{mOsm} / 1 \mathrm{H}_{2} \mathrm{O}$, dan pola osmoregulasinya berubah menjadi osmoregulator lemah (mendekati osmokonformer) dengan adanya ablasi. Pada pemeliharaan L. vannamei yang diablasi, sebaiknya memperhatikan kebutuhan media isoosmotik yaitu media dengan salinitas $25 \pm 1-29 \pm 1$ ppt (rentang isoosmotik intermolt akhir/premolt hingga molt).
\end{abstract}

Kata Kunci: Pola Osmoregulasi, Udang Vannamei, Diablasi, Dikultivasi, Tingkat Salinitas

\begin{abstract}
The purpose of this research is to examine the pattern of osmoregulation adult ablated L. vannamei and cultivated in media with different salinity. The method used isexperimental laboratories with Systematic Random Design (RAS) with 4 treatments and 3 replicates at each treatment. The treatments tested are treated with S1 salinity (10 ppt, $289.20 \mathrm{mOsm} / 1 \mathrm{H} 2 \mathrm{O}$ isosmotik postmolt), $\mathrm{S} 2$ (15 ppt, $432.80 \mathrm{mOsm} / 1 \mathrm{H}_{2} \mathrm{O}$ isosmotik initial intermolt), $\mathrm{S} 3\left(25 \pm 1 \mathrm{ppt}, 725.15 \mathrm{mOsm} / 1 \mathrm{H}_{2} \mathrm{O}\right.$ isosmotik intermolt end) and $\mathrm{S} 4\left(29 \pm 1 \mathrm{ppt}, 820.10 \mathrm{mOsm} / 1 \mathrm{H}_{2} \mathrm{O}\right.$ isosmotik molt). This study was conducted over 60 days. Data were analyzed by analysis of variance (ANOVA) one way, and to determine the effect difference between treatments carried Duncan's multiple range test. ANOVA results showed that the salinity effect on Osmotic Working Level (TKO), the frequency of molting and daily growth rate (before and after death), but does not affect the survival rate (SR) (p>0.05). Lowest TKO S3 are in treatment ( $25 \pm 1 \mathrm{ppt}) 1,01 \mathrm{mOsm} / 1 \mathrm{H} 2 \mathrm{O}$, and the pattern transformed into osmoregulator osmoregulasinya weak (approaching osmokonformer) with ablation. In the maintenance of $L$. vannamei were ablated, should pay attention to the needs of isosmotic media is media with a salinity of 25 $\pm 1-29 \pm 1 \mathrm{ppt}$ (range isosmotic intermolt end / premolt to molt).
\end{abstract}

Keywords: Osmoregulation Pattern, Vannamei Shrimp, Ablation, Cultivation, Salinity Level

Diterbitkan oleh:

Universitas Wiralodra

Jln. Ir. H. Juanda Km 3 Indramayu, Jawa Barat 


\section{PENDAHULAN}

Salah satu sumberdaya hayati perairan bernilai ekonomis penting dan telah dibudidayakan secara komersial adalah udang vaname (Litopenaeus vannamei). Widodo, Pantjara, Adhiyudanto \& Rachmansyah (2011) L. vannamei merupakan organisme eurihalin, dimana organisme tersebut dapat hidup dalam rentang salinitas yang luas. Udang vannamei mempunyai keunggulan antara lain lebih tahan penyakit, pertumbuhan lebih cepat, tahan terhadap gangguan lingkungan dan waktu pemeliharaan yaitu 90-100 hari yang lebih penting tingkat kelulushidupnya termasuk tinggi dan hemat pakan (Rahman, Rusliadi \& Putra, 2016). Berdasarkan hasil penelitian terdahulu, tingkat Kelulushidupan Dan Laju Pertumbuhan Udang Vaname sangat dipengaruhi oleh salinitas Air (Manan \& Putra, 2014; Fuady \& Nitisupardjo, 2013).

Salinitas merupakan faktor yang mempengaruhi tekanan osmosis pada udang, dimana semakin tinggi salinitas maka akan semakin tinggi pula tekanan osmosisnya. Sedangkan biota yang hidup di air asin harus mampu menyesuaikan diri terhadap tekanan osmosis yang berasal dari lingkungannya. Penyesuaian ini memerlukan banyak energi yang berasal dari pakan yang dikonsumsi sehingga dapat menurunkan efisiensi dari pakan tersebut (Kordi \& Tancung, 2007). Berdasarkan hal itu, maka perlu diketahui salinitas optimum untuk kehidupan L. vannamei yang diablasi. Ablasi mata merupakan salah satu faktor yang proses dimana agar proses molting pada udang menjadi lebih cepat, sehingga pertumbuhan dari udang tersebut menjadi lebih cepat dan masa pemeliharaannya menjadi lebih singkat. Namun, dengan adanya ablasi diduga akan terjadi kematian (Molt Death Syndrome) dikarenakan fungsi organ-x pada tangkai mata menjadi terganggu sehingga sekresi hormon osmoregulasi menjadi terganggu bahkan terhenti.

Selain itu, suatu sistem homeostatis pada udang untuk menjaga kemantapan milieu interiurnya dengan cara mengatur keseimbangan konsentrasi osmotik antara cairan intrasel dengan cairan ekstraselnya disebut osmoregulasi. Aktivitas tersebut dilakukan dengan cara mengatur volume air didalam cairan ekstrasel serta mengatur pertukaran ion antara cairan intrasel dengan cairan ekstrasel (Mantel \& Farmer, 1983). Oleh karena itu, untuk memelihara osmoregulasinya, udang harus hidup pada media yang mendukung pertumbuhannya.

Diterbitkan oleh:

Universitas Wiralodra

Jln. Ir. H. Juanda Km 3 Indramayu, Jawa Barat 
Berdasarkan hasil penelitian-penelitian berkaitan dengan osmoregulasi seperti (1) Anggoro, Suprapto \& Purwanti (2018) menyatakan bahwa pada media 25-26 \%o, karya theosmotic mengungkapkan level minimum dan meningkatkan laju pertumbuhan tanpa mengubah komposisi asam amino dalam jaringan tubuh udang. (2) Maghfiroh, Anggoro \& Purnomo (2019)didapatkan nilai osmolaritas media pada tambak intensif udang vaname di Mojo pada salinitas 20\%o berkisar 616-618 $\left(\mathrm{mOsm} / 1 \mathrm{H}_{2} \mathrm{O}\right)$ dan rata-rata TKO sebesar 37,36 (mOsm/l H O). (3) Chong-Robles et al (2014) menyatakan bahwa Pola euryhalinity dan osmoregulation berubah pada beberapa tahap perkembangan L. vannamei. Pola osmoregulasi hiper-hipo yang diperlihatkan oleh Juvenile dan Dewasa tampaknya dibentuk awal pada tahap pasca-larva pertama $\mathrm{PL}_{1}$ (pola osmoregulasi ontogenetik tipe 3), dengan toleransi yang lebih tinggi terhadap variasi salinitas yang diamati pada $\mathrm{PL}_{2}, \mathrm{PL}_{4}$ dan $\mathrm{PL}_{22}$. (4) Bückle, Barón \& Hernández (2006) menyatakan bahwa kondisi kombinasi T-S $32{ }^{\circ} \mathrm{C}$ dan $28 \%$ menghasilkan pertumbuhan terbaik pada udang vaname.

Penelitian-penelitian tersebut mengungkapkan kondisi pola osmoregulasi udang vannamei, namun tidak mengungkapkan pola osmoregulasi udang vannamei (litopenaeus vannamei) dewasa yang diablasi dan dikultivasi pada berbagai tingkat salinitas. Oleh sebab itu, penelitian ini bertujuan untuk mengkaji pola osmoregulasi, L. vannamei dewasa yang diablasi dan dikultivasi pada media dengan salinitas berbeda.

\section{METODE PENELITIAN}

Metode penelitian yang digunakan adalah metode eksperimental laboratories dengan sistem pengamatan dan perencanaan secara teratur terhadap fenomena yang diteliti (Sudjana, 1989). Eksperimen merupakan penyelidikan terencana untuk mendapatkan fakta baru atau memperkuat maupun membantah fakta yang sudah ada sebelumnya (Dwiloka \& Srigandono, 2006).

Rancangan percobaan yang digunakan adalah Rancangan Acak Sistematis (RAS) dengan mengaplikasikan 4 perlakuan dan 3 kali pengulangan agar diperoleh data yang lebih valid. Pada pengulangan pertama dilakukan untuk membuat statment, pengulangan kedua dilakukan untuk menguji kebenaran dari statment tersebut dan pengulangan ketiga digunakan untuk meyakinkan statment. 3 kali

Diterbitkan oleh: 
pengulangan dianggap sudah cukup mewakili dalam penelitian ini, karena apabila dilakukan pengulangan lebih dari 3 kalipun, hasilnya tidak akan jauh berbeda antara ulangan 1 dengan yang lain. Alasan lain dipilihnya 3 kali ulangan dalam penelitian ini adalah karena adanya limitasi metode seperti keterbatasan pengamat dalam pengamatan dan biaya. Perlakuan yang diterapkan adalah tingkat salinitas media yang penetapannya didasarkan pada fase molting udang (premolt, molt, postmolt, dan intermolt) melalui hasil penelitian pendahuluan. Menurut Nasoetion \& Barizi (1996), sesuai rancangan percobaan yang dipakai maka yang diacak adalah materi percobaan (udang). Sementara itu, penentuan tata letak perlakuan dan ulangan dilakukan secara sistematis.

Penelitian ini dilakukan dengan memasukkan L. vannamei dewasa yang telah di ablasi matanya ke dalam tiap-tiap wadah percobaan sesuai dengan tingkat salinitas yang telah ditentukan. Kepadatan setiap wadah berjumlah 1 ekor/wadah setelah sebelumnya dilakukan penimbangan udang tiap wadah percobaan $\left(\mathrm{W}_{0}\right)$. Pada awal percobaan dilakukan pengukuran osmolaritas haemolymph L. vannamei dan media percobaan dengan menggunakan Automatic Micro-Osmometer Roebling. Prosedur pengambilan haemolymph yaitu haemolymph diambil dari pericardiac cavity menggunakan jarum suntik ukuran $23 \mathrm{G}$ sebanyak 0,01 ml. Penelitian ini dilakukan selama 60 hari.

Peubah yang diteliti selama percobaan yaitu osmolaritas media dan pola osmoregulasi (disajikan pada Tabel 1.)

Tabel 1. Peubah yang Diteliti selama Percobaan Percobaan Peubah yang diteliti

\begin{tabular}{ll}
\hline Penelitian Pendahuluan & Osmolaritas media \\
Penelitian Inti/ Utama & Pola osmoregulasi \\
\hline
\end{tabular}

TKO dihitung berdasarkan selisih nilai osmolaritas haemolymph L. vannamei dengan osmolaritas media. TKO dihitung dengan rumus Che Mat (1987) dan Ferraris, et al. (1986) sebagai berikut :

$$
\mathrm{TKO}=\left[\mathrm{P}_{\mathrm{osm} \text { haemolymph }}-\mathrm{P}_{\mathrm{osm} \text { media }}\right]
$$

Diterbitkan oleh: 
Keterangan :

$\mathrm{TKO}=$ Tingkat kerja osmotik $\left(\mathrm{mOsm} / 1 \mathrm{H}_{2} \mathrm{O}\right)$

$\mathrm{P}_{\mathrm{osm} \text { haemolymph }}=$ Tekanan osmotik/osmolaritas haemolymph $\left(\mathrm{mOsm} / 1 \mathrm{H}_{2} \mathrm{O}\right)$

$\mathrm{P}_{\mathrm{osm} \text { media }}=$ Tekanan osmotik/osmolaritas media $(\mathrm{mOsm} / \mathrm{l} \mathrm{H} 2 \mathrm{O})$

[ $\quad]=$ Nilai mutlak

Data TKO dianalisis lebih lanjut dengan ANOVA, sebelum dilakukan pengujian. Sementara itu, untuk mengetahui pengaruh perlakuan terhadap TKO menggunakan uji pembanding ganda yaitu uji Duncan (Steel \& Torrie, 1981). Keseluruhan data dianalisis dengan menggunakan SPSS 16. Sementara itu, untuk mengetahui nilai optimum dari suatu kurva respon digunakan polinomial orthogonal yang diperoleh dengan menggunakan Microsoft Excel 2007.

\section{HASIL PENELITIAN DAN PEMBAHASAN}

Berdasarkan penelitian pendahuluan yang telah dilakukan diperoleh data osmolaritas udang yaitu $10 \mathrm{ppt}\left(289,20 \mathrm{mOsm} / 1 \mathrm{H}_{2} \mathrm{O}\right)$ setara dengan isosmotik postmolt, 15 ppt $\left(432,80 \mathrm{mOsm} / 1 \mathrm{H}_{2} \mathrm{O}\right)$ setara dengan isosmotik intermolt awal, $25 \pm 1$ ppt $(725,15$ $\left.\mathrm{mOsm} / 1 \mathrm{H}_{2} \mathrm{O}\right)$ setara dengan isosmotik intermolt akhir dan $29 \pm 1 \mathrm{ppt}\left(820.10 \mathrm{mOsm} / 1 \mathrm{H}_{2} \mathrm{O}\right)$ setara dengan isosmotik fase molt.

Penelitian yang telah dilakukan selama 60 hari, diperoleh data Tingkat Kerja Osmotik (TKO), osmolaritas haemolymph dan osmolaritas media. Data TKO, osmolaritas haemolymph dan osmolaritas media diperoleh pada awal penelitian dan akhir penelitian, selain itu keduanya dilakukan di Laboratorium Pengembangan Wilayah Pantai (LPWP) Jepara. Sementara itu, data frekuensi molting, pertumbuhan dan kelulushidupan diperoleh setiap 10 hari yang digunakan untuk membandingkan antar perlakuan. Data parameter kualitas air yang diperoleh melalui pengukuran setiap hari (pagi dan sore) digunakan sebagai data pendukung. Histogram TKO $\left(\mathrm{mOsm} / 1 \mathrm{H}_{2} \mathrm{O}\right)$ L. vannamei selama penelitian disajikan pada Gambar 1.

Diterbitkan oleh: 


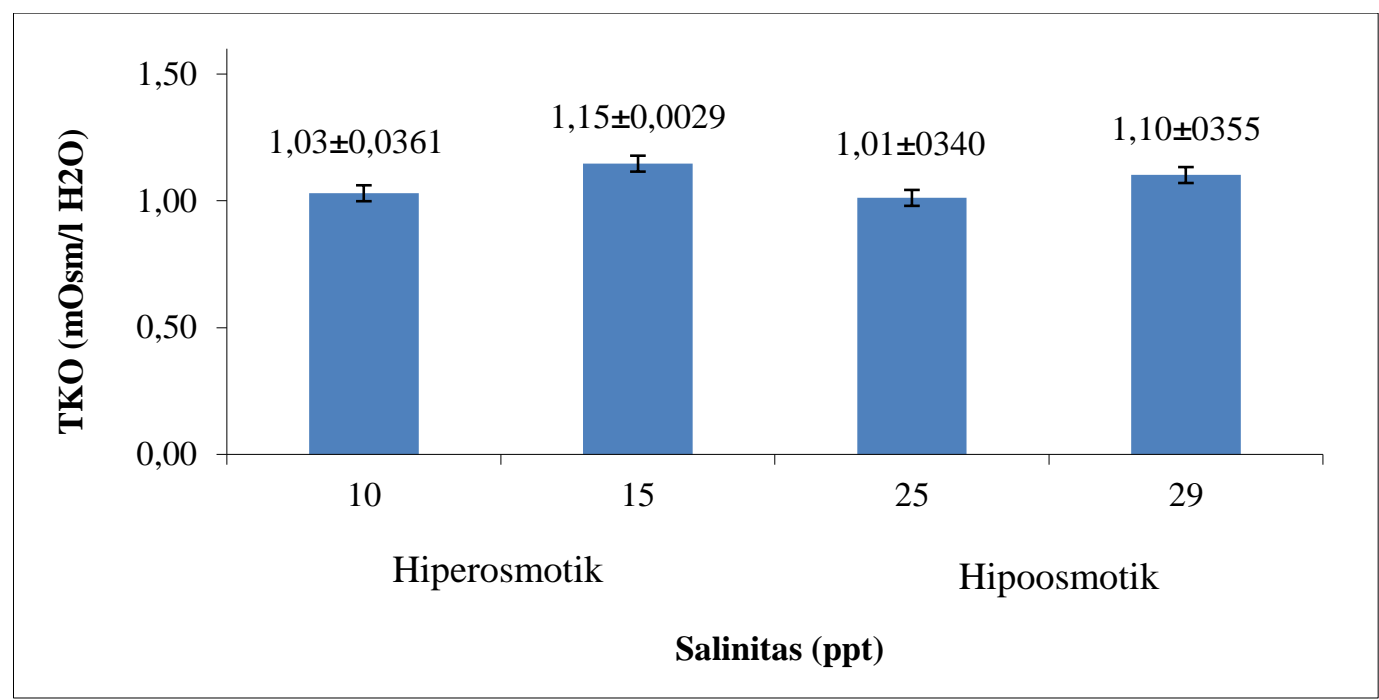

Gambar 1. Histogram Tingkat Kerja Osmotik (TKO) (mOsm/ $\left.\mathrm{H}_{2} \mathrm{O}\right)$ L. vannamei yang Diablasi dan Dikultivasi pada Berbagai Tingkat Salinitas

Berdasarkan histogram TKO di atas, diketahui bahwa tiap perlakuan memiliki nilai TKO yang berbeda. Nilai TKO perlakuan S1 yaitu media dengan salinitas 10 ppt setara dengan nilai sebesar 1,03 mOsm/ $/ \mathrm{H}_{2} \mathrm{O}$, perlakuan $\mathrm{S} 2$ yaitu media dengan salinitas $15 \mathrm{ppt}$ dengan nilai sebesar 1,15 mOsm/1 $\mathrm{H}_{2} \mathrm{O}$ yang merupakan nilai TKO terbesar, perlakuan $\mathrm{S} 3$ dengan salinitas $25 \pm 1$ ppt dengan nilai sebesar 1,01 mOsm/ $/ \mathrm{H}_{2} \mathrm{O}$ dimana merupakan nilai TKO terendah dan perlakuan S4 dengan salinitas $29 \pm 1$ ppt dengan nilai sebesar 1,10 $\mathrm{mOsm} / \mathrm{l} \mathrm{H}_{2} \mathrm{O}$.

Hasil uji normalitas dan homogenitas pada berbagai tingkat salinitas. TKO $L$. vannamei diperoleh hasil data yang menyebar normal dan homogen karena nilai $\mathrm{P}>0,05$. Hal ini memenuhi syarat untuk dianalisis lebih lanjut dengan analisis varian (ANOVA). Berdasarkan ANOVA TKO, dapat diketahui bahwa salinitas berpengaruh terhadap TKO $(\mathrm{P}<0,05)$. Perbedaan antar perlakuan diketahui dengan melakukan uji Duncan, dimana hasil pengujian tersebut disajikan pada Tabel 2 .

Tabel 2 Uji Duncan Tingkat Kerja Osmotik (TKO) (mOsm/l $\left.\mathrm{H}_{2} \mathrm{O}\right)$ L. vannamei yang Diablasi dan Dikultivasi pada Berbagai Tingkat Salinitas 


\begin{tabular}{|c|c|c|c|c|c|c|}
\hline \multirow[b]{2}{*}{$\begin{array}{c}\text { (I) } \\
\text { Salinitas }\end{array}$} & \multirow[b]{2}{*}{$\begin{array}{c}(\mathrm{J}) \\
\text { Salinitas }\end{array}$} & \multirow[b]{2}{*}{$\begin{array}{c}\text { Mean Difference } \\
(\mathrm{I}-\mathrm{J})\end{array}$} & \multirow[b]{2}{*}{ Std. Error } & \multirow[b]{2}{*}{ Sig. } & \multicolumn{2}{|c|}{$\begin{array}{l}\text { 95\% Confidence } \\
\text { Interval }\end{array}$} \\
\hline & & & & & $\begin{array}{l}\text { Lower } \\
\text { Bound }\end{array}$ & $\begin{array}{l}\text { Upper } \\
\text { Bound }\end{array}$ \\
\hline \multirow[t]{3}{*}{$\mathrm{S} 1$} & S2 & $-.12000^{*}$ & .02438 & .001 & -.1762 & -.0638 \\
\hline & S3 & .01667 & .02438 & .514 & -.0396 & .0729 \\
\hline & S4 & $-.07333^{*}$ & .02438 & .017 & -.1296 & -.0171 \\
\hline \multirow[t]{3}{*}{ S2 } & S1 & $.12000^{*}$ & .02438 & .001 & .0638 & .1762 \\
\hline & S3 & $.13667^{*}$ & .02438 & .001 & .0804 & .1929 \\
\hline & S4 & .04667 & .02438 & .092 & -.0096 & .1029 \\
\hline \multirow[t]{3}{*}{ S3 } & S1 & -.01667 & .02438 & .514 & -.0729 & .0396 \\
\hline & S2 & $-.13667^{*}$ & .02438 & .001 & -.1929 & -.0804 \\
\hline & S4 & $-.09000^{*}$ & .02438 & .006 & -.1462 & -.0338 \\
\hline \multirow[t]{3}{*}{ S4 } & S1 & $.07333^{*}$ & .02438 & .017 & .0171 & .1296 \\
\hline & S2 & -.04667 & .02438 & .092 & -.1029 & .0096 \\
\hline & S3 & $.09000^{*}$ & .02438 & .006 & .0338 & .1462 \\
\hline
\end{tabular}

$*$ perbedaan rata-rata adalah signifikan pada 0,05

Hasil uji pembanding Duncan menunjukkan bahwa terdapat perbedaan pengaruh antara perlakuan S1-S2, S1-S4, S3-S2, S3-S4, sedangkan antara perlakuan S1S3, S2-S4 tidak terdapat perbedaan pengaruh. Hubungan respon osmolaritas haemolymph L. vannamei yang diablasi dan dikultivasi pada berbagai tingkat salinitas media disajikan pada Gambar 2.

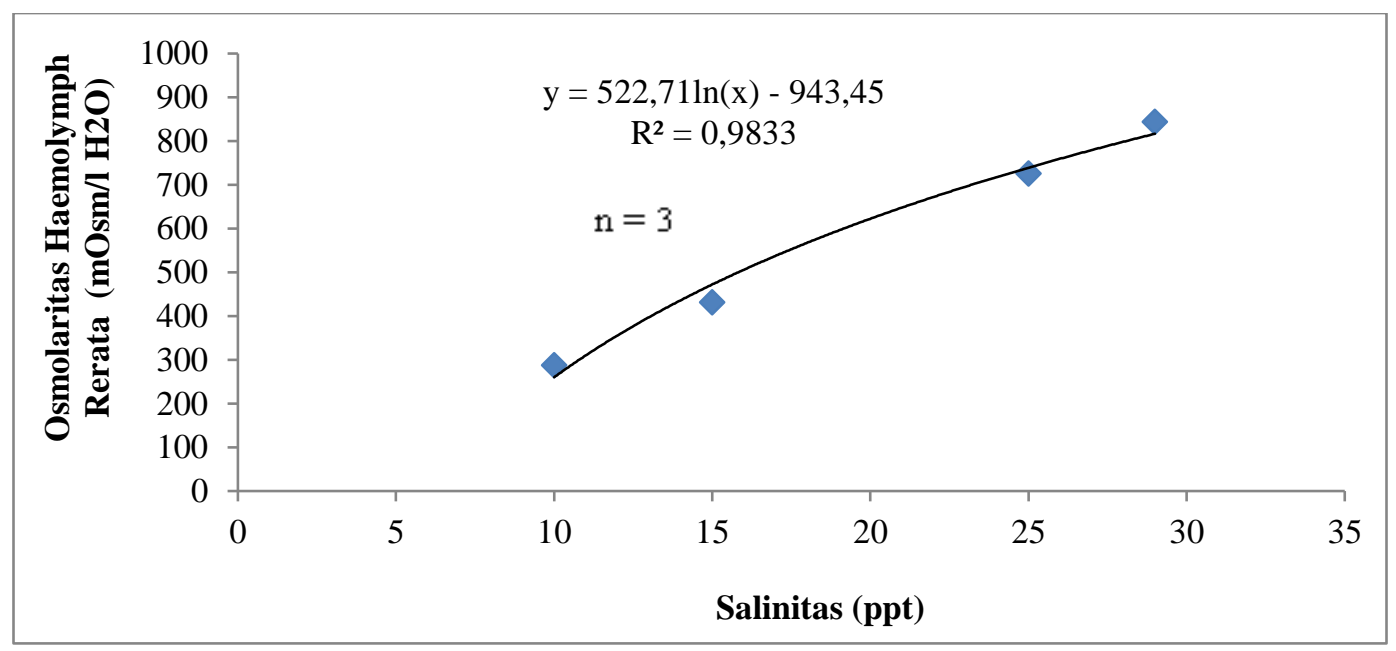

Gambar 2. Kurva Osmolaritas Haemolymph $\left(\mathrm{mOsm} / 1 \mathrm{H}_{2} \mathrm{O}\right)$ L. vannamei yang Diablasi dan Dikultivasi pada Berbagai Tingkat Salinitas 
Model respon osmolaritas haemolymph L. vannamei pada berbagai tingkat salinitas adalah sebagai berikut :

$$
\hat{y}=522,7 \ln (\mathrm{x})-943,4 \text { dengan } \mathrm{R}^{2}=0,983
$$

Model persamaan tersebut dapat digunakan untuk memperkirakan respon $\mathrm{Y}$ (osmolaritas haemolymph) apabila X (salinitas) diketahui. Berdasarkan hasil dari persamaan di atas, mempunyai arti pada $\mathrm{R}^{2}=0,983$ yakni $98,3 \%$ faktor salinitas mempengaruhi osmolaritas haemolymph L. vannamei.

\section{Pembahasan}

Osmoregulasi merupakan upaya organisme akuatik untuk mempertahankan keseimbangan cairan tubuh (haemolymph) dengan cairan ekternal (media). Kemampuan osmoregulasi udang Penaeid dipengaruhi oleh beberapa faktor antara lain jenis kelamin, suhu, periode aklimatisasi, siklus hidup dan siklus ganti (Williams, 1960; Haefner, 1969). L. vannamei bersifat osmoregulator lemah (mendekati osmokonformer) yang diakibatkan oleh adanya perlakuan ablasi, yang menyebabkan terganggunya hormon. Hal tersebut dikarenakan udang yang diablasi akan terganggu fungsi organ-x serta sekresi hormon osmoregulasinya, sehingga tidak memiliki kemampuan dalam mengatur kadungan elektrolit (osmoefektor) serta osmolaritas didalam cairan internalnya, akibat osmolaritas haemolymph mengikuti osmolaritas media (salinitas) (Anggoro \& Nakamura, 1996).

Hasil pengujian dan perhitungan statistik menunjukkan bahwa akibat salinitas yang berbeda pada media memberikan pengaruh yang nyata $(\mathrm{P}<0,05)$ terhadap TKO $L$. vannamei yang diablasi. Pada perlakuan S1 (10 ppt), S2 (15 ppt), S3 (25 \pm 1 ppt), dan S4 $(29 \pm 1$ ppt). Nilai osmolaritas haemolymph relatis lebih rendah dari osmolaritas media. Hal ini menunjukkan bahwa L. vannamei mengalami regulasi hipoosmotik. Menurut Anggoro (2000), bahwa osmoregulasi hipoosmotik atau hiperosmotik tersebut dilakukan untuk mempertahankan sistem keseimbangan antara cairan tubuh (haemolymph) dan cairan medianya, dimana pertukaran elektrolit tersebut dilakukan dengan cara transpor aktif melalui insang.

L. vannamei yang diablasi tidak memiliki salinitas optimal bagi TKO, karena sifatnya yang osmoregulator lemah (mendekati osmokonformer) dimana osmolaritas haemolymph cenderung mengikuti osmolaritas media. Namun, berdasarkan hasil penelitian

Diterbitkan oleh:

Universitas Wiralodra

Jln. Ir. H. Juanda Km 3 Indramayu, Jawa Barat 
yang disajikan dalam histogram dan garfik polinomial TKO L. vannamei yang diablasi menunjukkan bahwa salinitas dengan TKO terendah berada pada perlakuan S3 (25 $\pm 1 \mathrm{ppt})$ yang berarti mndekati isoosmotik, dengan nilai TKO sebesar 1,01 mOsm/ $1 \mathrm{H}_{2} \mathrm{O}$. Menurut Che Mat (1987), TKO terendah terdapat pada media yang mendekati isoosmotik disebabkan oleh dua faktor. Faktor pertama karena rendahnya transport aktif ion dan pertukaran osmoefektor yang kedua aktivitas enzim Na-K-ATPase berada dalam tingkat yang maksimum.

\section{KESIMPULAN}

Kesimpulan yang dapat diambil dari penelitian yang telah dilakukan adalah pola osmoregulasi Litopenaeus vannamei mengalami perubahan dari osmoregulator menjadi osmokonformer diakibatkan oleh adanya perlakuan ablasi, dimana osmolaritas haemolymph mengikuti osmolaritas media. Oleh karena itu, L. vannamei tidak memiliki salinitas optimal pada TKO. Namun berdasarkan penelitian nilai terendah TKO berada pada perlakuan S3 (25 $\pm 1 \mathrm{ppt}$ ) dengan nilai TKO sebesar 1,01 mOsm/1 $\mathrm{H}_{2} \mathrm{O}$ (mendekati isoosmotik intermolt akhir/premolt). Tingkat salinitas media isoosmotik pada berbagai fase molting memberikan pengaruh TKO L. vannamei.

\section{UCAPAN TERIMA KASIH}

Terima kasih saya ucapkan kepada Bapak Prof. Dr. Ir. Sutrisno Anggoro, MS dan Ibu Ir. Siti Rudiyanti, M.Si yang telah banyak membantu dalam penelitian ini baik moril maupun materil sehingga penelitian ini bisa dilaksanakan dengan baik dan tepat pada waktunya.

\section{DAFTAR PUSTAKA}

Anggoro, S. (2000). Pola Regulasi Osmotik dan Kerja Enzim Na-K-ATPase Udang Windu (Penaeus monodon Fab) pada Berbagai Fase Molting. Aquaculture Indonesia, Vol 1, No 2, 15-21.

Anggoro, S dan K. Nakamura. (1996). Osmoregulation of Kuruma Prawn (Penaeus Japonicus). Bull.Kagoshima, Vol 2, No 3, 14-19.

Anggoro, S., Suprapto, D., \& Purwanti, F. (2018). Osmoregulation Pattern of Fingerling Vanname Shrimp (Litopenaeus vannamei) Rearing in Three Molt Stage Iso-Osmotic

Diterbitkan oleh:

Universitas Wiralodra

Jln. Ir. H. Juanda Km 3 Indramayu, Jawa Barat 
Media. Ilmu Kelautan: Indonesian Journal of Marine Sciences, Vol 23, No 3, 119122.

Bückle, L. F., Barón, B., \& Hernández, M. (2006). Osmoregulatory capacity of the shrimp Litopenaeus vannamei at different temperatures and salinities, and optimal culture environment. Revista de biología tropical, Vol 54, No 3, 745-753.

Che Mat, C. R. 1987. Kajian Ekofisiologi dan Biokimia Macrobrachium rosenbergii dan Hubungannya dengan Akuakultur. Kumpulan Laporan Penyelidikan Sains Fisis Gunaan. Fakultas Sains dan Gunaan, Universitas Kebangsaan Malaysia. Bangi.

Chong-Robles, J., Charmantier, G., Boulo, V., Lizárraga-Valdéz, J., Enríquez-Paredes, L. M., \& Giffard-Mena, I. (2014). Osmoregulation pattern and salinity tolerance of the white shrimp Litopenaeus vannamei (Boone, 1931) during post-embryonic development. Aquaculture, 422-423, 261267. doi:10.1016/j.aquaculture.2013.11.034.

Dwiloka, B dan B. Srigandono. (2006). Metodologi Penelitian. Universitas Diponogoro, Semarang, $219 \mathrm{hlm}$.

Ferraris, R. P., E. D. P. Estepa, J. M. Ladja dan E. G. D. Jesus. (1986). Osmoregulation in Penaeus monodon: Effect of Molting and External Salinity. p: 637-640. In J. L. Maclean et. al., eds. Asian Fish. Soc., Manila.

Fuady, M. F., \& Nitisupardjo, M. (2013). Pengaruh Pengelolaan Kualitas Air Terhadap Tingkat Kelulushidupan Dan Laju Pertumbuhan Udang Vaname (Litopenaeus Vannamei) Di PT. Indokor Bangun Desa, Yogyakarta. Management of Aquatic Resources Journal, Vol 2, No 4, 155-162.

Haefner. Jr. A. P. (1969). Osmoregulation of Crangon septemspinosa Say (Crustacea: Caridae). Biol. Bull., 137:438-446.

Kordi, M. G. H., dan A. B. Tancung. (2007). Pengelolaan Kualitas Air dalam Budidaya Perairan. Jakarta: Rineka Cipta

Maghfiroh, A., Anggoro, S., \& Purnomo, P. W. (2019). Pola Osmoregulasi dan Faktor Kondisi Udang Vaname (Litopenaeus Vannamei) Yang Dikultivasi di Tambak Intensif Mojo Ulujami Pemalang. Management of Aquatic Resources Journal, Vol 8, No 3, 177-184.

Manan, A., \& Putra, F. R. (2014). Monitoring Kualitas Air pada Tambak Pembesaran Udang Vannamei (Litopenaeus vannamei) di Situbondo, Jawa Timur. Jurnal Ilmiah Perikanan dan Kelautan, Vol 6, No 2, 137-142.

Mantel, L. H dan L. L. Farmer. (1983). Osmotic and Ionic Regulation, $p: 53-161$. In Mantel, (ed) The Biology of Crustacea, Vol.5 Academic Press, New York. 
Nasoetion, A. H. dan Barizi. (1996). Perancangan Percobaan Bidang Pertanian dan Biologi. Departemen Statistika dan Komputasi, IPB. Bogor.

Rahman, F., Rusliadi, R., \& Putra, I. (2016). Growth And Survival Rate Of Western White Prawns (Litopaneaus Vannamei) On Different Salinity (Doctoral dissertation, Riau University).

Steel, R. G. D. dan J. H. Torrie. (1993). Prinsip dan Prosedur Statistika (Suatu Pendekatan Biometrik). Jakarta: PT. Gramedia Pustaka Utama

Williams, A. B. (1960). The influence of temperature on osmotic regulation in two species of estuarine shrimps (Penaeus). The Biological Bulletin, Vol 119, No 3, 560-571

Widodo, A. F., Pantjara, B., Adhiyudanto, N. B., \& Rachmansyah, R. (2011). Performansi Fisiologis Udang Vaname, Litopenaeus Vannamei Yang Dipelihara Pada Media Air Tawar Dengan Aplikasi Kalium. Jurnal Riset Akuakultur, 6(2), 225-241. 